\title{
The Effects of Maternal Anemia in Pregnant Women with Respect to the Newborn Weight and the Placental Weight in the Delivery Room
}

\author{
๑ Nurdan Tekgül1, @ Mustafa Yamazhan² \\ 1 University of Health Sciences, Tepecik Training and Research Hospital, Clinic of Family Medicine, i̇zmir, Turkey \\ 2University of Health Sciences, Tepecik Training and Research Hospital, Clinic of Obstetrics and Gynecology, İzmir, Turkey
}

\begin{abstract}
Aim: The aim of the study was to investigate the possible effects of maternal anemia in pregnant women with respect to placental weight and newborn weight.

Materials and Methods: In this cross-sectional study, 68 healthy pregnant women were included from the $2^{\text {nd }}$ Izmir Atatürk Training and Research Hospital, Clinic of Obstetrics and Gynecology. Maternal anemia was defined with a hemoglobin value less than $10 \mathrm{~g} / \mathrm{dL}$. The correlations were studied between the parameters (hemoglobin levels, placental weight and newborn weight) in primiparous and multiparous women.

Results: The study cohort consisted of 36 (52\%) multiparous and 32 (48\%) primiparous women (mean age \pm standard deviation: $27.40 \pm 7.23$ years (range: $17-45$ years). The mean age of the newborns was 39.8 weeks. The rate of gestational anemia was as $27 \%$. The rate for multıparous pregnant women $(31.7 \%)$ was four times higher rates anemia compared to the rate of primiparous pregnant woman (8.3\%). A positive correlation was found between placental weight and child weight ( $\mathrm{R}: 0.657$, t value: 0.00$)$. There was a weak negative correlation between placental weight and hemoglobin $(\mathrm{Hb})$ values. However, there was no statistically significant correlation between maternal $\mathrm{Hb}$ values and neonatal weight.

Conclusion: Maternal anemia is an important and frequently encountered antenatal problem for pregnant women and it should be investigated in pregnant women and as well as candidates for pregnancy.
\end{abstract}

Keywords: Maternal anemia, placental weight, newborn weight

\section{Introduction}

Maternal anemia has been reported as the most common hematologic problem in pregnant women. This disorder occurs frequently as a result of insuffucient intake of iron and folic acid during pregnancy (1-4). It is reported that iron deficiency anemia occurs in $85-100 \%$ pregnant women with insufficient supplementation of iron during pregnancy $(5,6)$. The rate and severity of maternal anemia has some variabilities in the different geographic and economical distribution (5). While many women in developed countries start pregnancy with low iron stores, this is much more serious in developing countries. Maternal anemia in the gestational period may also be related to obstetric complications such as postpartum hemorrhage, operative delivery and placental abnormalities $(5,6)$.

\section{Address for Correspondence}

Nurdan Tekgül MD, University of Health Sciences, Tepecik Training and Research Hospital, Clinic of Family Medicine, İzmir, Turkey Phone: +90 5325402025 E-mail: nurdantekgul1@hotmail.com ORCID: orcid.org/0000-0001-7495-1798 Received: 18.09.2019 Accepted: 26.09.2019 
Maternal anemia might cause serious fetal and maternal complications during pregnancy (7). The effects of this disorder on the placenta and child weight have been reported in the several studies (8-11). Anemia with hemoglobin levels between 6-10 g/dL might cause placental hypertrophy during the pregnancy. A retrospective study from Oxford, England showed a correlation between maternal iron deficiency anemia and increased placental weight and placental/ birth weight ratio (12). Some correlation between maternal anemia and low economic environment conditions and high morbidity of the newborn has been reported (13-17). Maternal anemia may also be associated with prematurity, low birth weight, miscarriages and even fetal death, even at moderate hemoglobin $(\mathrm{Hb})$ levels of $8-11 \mathrm{~g} / \mathrm{dL}(18,19)$.

The aim of this cross-sectional clinical study was to investigate the possible effects of maternal anemia in primiparous and multiparous pregnant woman with respect to placental weight and child weight in the west part of Turkey.

\section{Materials and Methods}

The study retrospectively included 68 pregnant women who were admitted to the $2^{\text {nd }}$ Izmir Atatürk Training and Research Hospital, Clinic of Obstetrics and Gynecology.

Exclusion criteria was hereditary blood disease, systemic disease, hemorrhagic diathesis, non-gastrointestinal system disease that could lead to continuous blood loss, third trimester hemorrhage, premature rupture of membranes, hemolytic anemia and laboratory tests without $\mathrm{Rh}$ incompatibility.

A venous blood sample was taken from the pregnant women in the first stage of labor and $\mathrm{Hb}$ levels were measured. Gestational anemia was defined as a hemoglobin value of less than $10 \mathrm{~g} / \mathrm{dL}$. Weights of babies and placentas were measured in the delivery room by the same researcher (NT) after delivery.

Due to the commencement of labor, pregnant women were admitted to the clinic and the following parameters were recorded in order to compile the information in the patient files of all pregnant women: 1) Vital signs (body temperature, pulse, blood pressure, body weights and heights), 2) age, education level, socio-economic status, smoking and use of substances poor for the health, 3) complaints and anamnesis of application (systemic diseases such as diabetes, hypertension, heart failure, kidney disease, familial hematological diseases, presence of bleeding diathesis and previous operations), 4) obstetric anamnesis (gravid, parity, evacuation curettage, spontaneous abortion and number of living children), 5) presence of conditions that may make pregnancy risky in previous pregnancies, infant mortality, $3^{\text {rd }}$ trimester and/or postpartum hemorrhage, how previous pregnancies ended, drug use, use of vitamins and especially iron preparations, diseases during pregnancy, trauma, surgery, 6) blood groups, 7) general systemic and obstetric examination (gestational week, fetal size, presentation, whether the presenting part is engaged, uterine tone during contraction and resting phase, etc.), 8) vaginal examination (cervical opening, wiping, coming part, height of the coming part, bone and soft tissue parts of birth canal) in patients with no bleeding that may be dangerous by examining whether there is bleeding in antenatal period in the current pregnancy.

The study was approved by Ethical Committee of Atatürk Training and Research Hospital (approval number: 47, date: 03.08.1999).

\section{Statistical Analysis}

In the statistical analysis, correlation between all biochemical and demographic parameters with Spearman Correlation Analysis test was investigated.

\section{Results}

Demographic Characteristics: The study included 36 (52\%) multiparous and 32 (48\%) primiparous women. The mean age of the pregnant women in the study cohort was 27.40 years [standard deviation (SD) +7.23 age range: 17 -yearold primigravid and 45-year-old multigravida]. The mean gestational week of the newborns was 39.8 weeks of age (SD: 0.97).

Maternal Anemia, Placenta Weight and Child Weight: The maternal anemia was defined in 18 of 68 pregnant woman (27\%). Multiparous pregnant women (31.7\%) had four times higher rates of anemia compared to the rate of primiparous pregnant women (8.3\%).

We compared the $\mathrm{Hb}$ levels and placenta weight of the pregnant woman and child weight at the delivery according the gravida number of the pregnant woman in the two groups (group 1: Primiparous versus, group 2: Multiparous). There were no statistically significant differences between two groups for the $\mathrm{Hb}$ levels, placenta weight and child weight respectively $(p=0.31, p=0.75, p=0.65, p>0.05)$ in Table I.

The Correlation Between Maternal Anemia, Placenta Weight and Child Weight: A possible correlation was studied between the studied parameters $(\mathrm{Hb}$, placental weight and child weight). There was no positive or negative 
correlation between maternal $\mathrm{Hb}$ values and child weight (R: 0.26, t value: 0.41). However, there was a weak negative correlation between placental weight and $\mathrm{Hb}$ values in the whole group. (R: -0.23 , t value: 0.02 , R square: 0.56 ) (Figure 1). A positive correlation was found between placental weight and child weight. (R: 0.657, t value: 0.00) (Figure 2). However, there was no statiscally significant correlation (positive or negative) between maternal $\mathrm{Hb}$ values and child weight. (R: 0.26, t value: 0.41, R square: 0.00) (Figure 3).

\section{Discussion}

According to World Health Organization reports, maternal anemia has been reported as the most common form of anemia in pregnancy, which occurs as a result of insuffucient intake of iron and folic acid during pregnancy (20). In this study, the rate of maternal anemia was defined as $27 \%$ in the total cohort of primiparous and multiparous pregnant women. Multiparous pregnant women (31.7\%) had four times higher rates of anemia compared the rate for primiparous pregnant women (8.3\%).

The rate of anemia in pregnant women was compatible with the rates of reported in the previous studies (between $25 \%$ to $58 \%$ ) (17-19). In their study, Prual et al. (21) reported the rate of gestational anemia at $25 \%$ of pregnant women in Chad. Lijestrand et al. (22) reported anemia in $58 \%$ of the pregnant

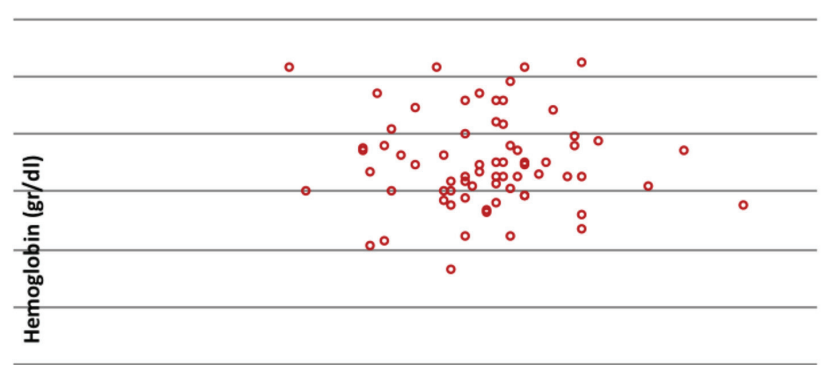

Child wight (kg)

Figure 1. A weak negative correlation between placental weight and hemoglobin values (R: -0.23 , t value: 0.02 ) women with $\mathrm{Hb}$ levels below $11.0 \mathrm{gr} / \mathrm{dL}$ in $58 \%$ of pregnant women. Our study and previous studies identified higher rates of gestational anemia in multiparous pregnant women compared with the rate of gestational anemia in primiparous women. These results indicate that the multiparous pregnant woman should be more carefully followed and supported with iron and folic acid supplementation.

In the present study we also studied the correlation between the parameters ( $\mathrm{Hb}$, placental weight and child weight). A positive correlation was found between placental weight and child weight. However, there was a weak negative

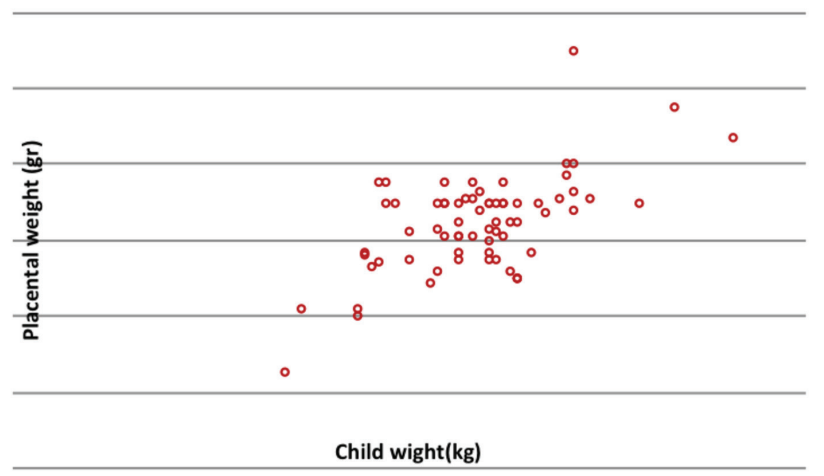

Figure 2. A positive correlation was found between placental weight and child weight ( $R: 0.657$, $t$ value: 0.00 )

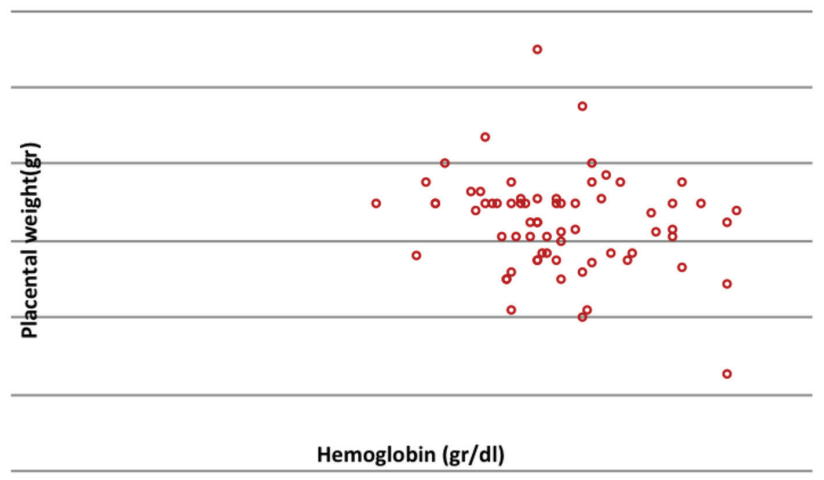

Figure 3. No statiscally significant correlation (positive or negative) between maternal hemoglobin values and child weight. (R: $0.26, t$ value: 0.41 )

\begin{tabular}{|l|l|l|l|l|}
\hline \multirow{4}{*}{ Table I. The comparison of hemoglobin, placental weight, and child weight in primiparous and multiparous pregnant woman } \\
\hline & Group 1 & Group II & Total \\
\cline { 2 - 5 } & Primiparous Pregnant Woman & Multiparous Pregnant Woman & Pregnant Woman & p-value \\
\cline { 2 - 5 } & $\mathbf{n}=\mathbf{3 2 ,}$ Mean \pm SD & $\mathbf{n}=\mathbf{3 6}$, Mean \pm SD & $\mathbf{n = 6 8 , ~ M e a n ~} \pm$ SD & \\
\hline Hb (gr/dL) & $11.27 \pm 1.37$ & $10.88 \pm 1.69$ & $10.99 \pm 1.60$ & 0.31 \\
\hline Placenta weight (gr) & $632.91 \pm 121.94$ & $652.50 \pm 129.27$ & $647.6 \pm 125.95$ & 0.65 \\
\hline Child weight $(\mathrm{kg})$ & $3.13 \pm 0.49$ & $3.30 \pm 0.54$ & $3.25 \pm 0.55$ & 0.75 \\
\hline
\end{tabular}

SD: Standard deviation, Hb: Hemoglobin 
correlation between placental weight and $\mathrm{Hb}$ values in the whole group. Wheeler et al. (23) reported that placental growth was determined by maternal factors prevailing before conception. They stated that maternal anemia is one of the environmental factors associated with increased placental weight at birth and thought that these factors modified angiogenesis in trophoblastic villi.

Previously, a few clinics studies reported that increased placental weight and hypertrophy are associated with maternal anemia. $(4,24,25)$. The placenta weight to newborn weight ratio was found to increase in patients with anemia (26).

However, there was no statistically significant correlation (positive or negative) between maternal $\mathrm{Hb}$ values and child weight. However, although there is a contradiction in this issue in the literature, it has been found in some studies that placental weight increases with maternal anemia. In a prospective cohort study conducted by Williams et al. (27) in 1997 among 2507 pregnant women in Australia, placental weight was found to increase with maternal anemia. In the same study, gestational age was also positively correlated with an increase in placental weight. However, it was added that the ratio of placental weight to birth weight is not an accurate indicator for fetal growth. In a study conducted in 1991, it was reported that the higher the placental weight, the lower the $\mathrm{Hb}$ level and the mean maternal erythrocyte volume. The ratio of placental weight to birth weight was highest in the most anemic mothers. In addition, mother's smoking reduces placenta weight (28).

\section{Study Limitations}

There are several limitation of this cross-sectional study. First, the small number of patients in the present study is a major limitation of the study. This scarity did not allow us to conduct a etiologic subgroup categorization of maternal anemia (iron deficiency, folic acid deficiency Vitamin B12 deficiency, obstetric complications such as postpartum hemorrhage, operative delivery and placental abnormalities) as well as the the severity of gestational anemia. A second limitation is the lack of the histopathologic evaluation of maternal placenta. Thirdly, we did not conduct a follow-up measurement of the newborns at the $21{ }^{\text {st }}$ day of life to access the newborn weight without the maternal edema effects.

\section{Conclusion}

The placenta and fetal organ systems are able to compensate for maternal anemia without any major complications, that is, the child is somehow protected from anemia.

\section{Ethics}

Ethics Committee Approval: The study was approved by Ethical Committee of Atatürk Training and Research Hospital (approval number: 47, date: 03.08.1999).

Informed Consent: Retrospective study.

Peer-review: Externally peer-reviewed.

\section{Authorship Contributions}

Surgical and Medical Practices: N.T., M.Y., Concept: N.T., M.Y., Design: N.T., M.Y., Data Collection or Processing: N.T., M.Y., Analysis or Interpretation: N.T., M.Y., Literature Search: N.T., M.Y., Writing: N.T., M.Y.

Conflict of Interest: None of the authors had conflict of interest.

Financial Disclosure: The authors declared that this study received no financial support.

\section{References}

1. Mumbare S, Maindarkar G, Darade R, Yenge S, Tolani MK, Patole K. Maternal risk factors associated with term low birth weight neonates: A matched-pair case control study. Indian Pediatr 2012;49:25-8.

2. Esendal AS. Gebelikte kan hastalıkları, gebelik ve sistemik hastalıklar. Ankara Üniversitesi Basımevi 1976;356-89.

3. Biswas M, Perloff D. Cardiak, hematologic, pulmonary and renal and urinary tract disorders in pregnancy, In: Current obstetric and gynocologic diagnosis and treatment. Lange Medical Publications 1987;367-8.

4. Kathy G, John CM. Anemia associated with pregnancy. In: Sciarra IJ Gynecology and Obstetrics, Volume 3. Philedelphia JB. Lippincott Company 1992;1-42.

5. Samuels P. Hematologic complications of pregnancy, In: Obstetrics: Normal and problem pregnancies, (3rd edition). Churchill Livingstone Inc. 1996.p.1083-100.

6. Kuyumcuoğlu $U$, Uludoğan M. Maternal-plasental fetal ünite. İn: Kişnişçi HA, Gökşin E, Durukan T, et al. editors. Temel kadın hastalıkları ve doğum Bilgisi. Ankara, Güneş Kitabevi; 1996.p.189-195,364.

7. Goudet S, Murira Z, Torlesse H, Hatchard J, Busch-Hallen J. Effectiveness of programme approaches to improve the coverage of maternal nutrition interventions in South Asia. Matern Child Nutr. 2018;14; 12699, 2018

8. Lebrun A, Plante AS, Savard C, Dugas C, Fontaine-Bisson B, Lemieux S3, Robitaille J, Morisset AS. Tracking of Dietary Intake and Diet Quality from Late Pregnancy to the Postpartum Period. Nutrients, 3;11-19, 2019.

9. Bailey RL, Pac SG, Fulgoni VL, Reidy KC, Catalano PM. Estimation of Total Usual Dietary Intakes of Pregnant Women in the United States. JAMA Netw Open. 5;2-6, 2019

10. Hahn KA, Wesselink AK, Wise LA, Mikkelsen EM, Cueto HT, Tucker KL, Vinceti M, Rothman KJ, Sorensen HT, Hatch EE. Iron Consumption Is Not Consistently Associated with Fecundability among North American and Danish Pregnancy Planners. I Nutr. 49(9):1585-1595,2019. 
11. Steer PJ. Maternal hemoglobin concentration and birth weight. Am J Clin Nutr 2000;71:1285-7.

12. Gogfrey KM, Redman CWG, Barker DJ, Osmond C. The effect of maternal anaemia and iron deficiency on the ratio of fetal weight to plasental weight. Br J Obstet Gynaecol 1991;8:88691.

13. Elizabeth AL, Warwick R. Hematological problems, In: High risk pregnancy management options. London W.B. Saunders Company; 1996.p.337-72.

14. Dewhurst C). Blood disorders in pregnancy, In: Integrated Obstetrics and Gynaecology for Postgraduates, Oxford, Blackwell Scientific Publications; 1996.p.316-23.

15. Fenton V, Cavill I, Fisher ). Iron stores in pregnancy. Br ) Haematol 1977;37:145-9.

16. Krawinkel MB, Bethge $M$, El Karib AO, Ahmet HM, Mirghani OA. Maternal ferritin values and fetal iron stores. Acta Paediatr Scand. 1990;79:467.

17. Colomer I, Colomer C, Gutierrez D, et al. Anaemia during pregnancy as a risk factor for infant iron deficiency: Report from the valencia infant anaemia cohort (VIAC) study, Paediatric and Perinatal Epidemiology 1990;4:196-204.

18. Addy DP. Happiness is Iron, Br Med J 1986;292:969-70.

19. Samuels P. Hematologic complications of pregnancy, In: Obstetrics: Normal and problem pregnancies, (3rd edition). Churchill Livingstone Inc 1996.p.1083-100.

20. World Health Organization: Nutritional Anaemias, Technical Report Series.No: 53, Genova, W.H.O., 1972.
21. Prual A, Galan P, De Bernis L, Hercber S. Evaluation of Iron statusin chadian pregnant women: consequences of maternal iron deficiency on the haematopoietic status of newborns. Trop Georg Med 1988;40:1-6.

22. Lijestrand J, Bergström S, Birgegård G. Anaemia of pregnancy in mozambique, Transactions of the royal society of tropical medicine and hygiene 1986;80:249-55.

23. Wheeler T, Sollero C, Alderman S, Landen I, Anthony F, Osmond C. Relation between maternal haemoglobin and plasental hormone concentrations in early pregnancy. Lancet 1994;343:511-3.

24. Michael Gr, Ervin MG, Bissondette J. Plasentaland fetal physiology, In: Obstetrics: Normal and Problem Pregnancies, (3rd edition). Churchill Livingstone Inc 1996.p.65-90.

25. Dewhurst C). Blood disorders in pregnancy, In: Integrated Obstetrics and Gynaecology for Postgraduates. Oxford. Blackwell Scientific Publications; 1992.p.316-23.

26. Stoz F, Schultz R, Kohne E, Schuhmann RA. Correlation between maternal hemoglobin levels and plasental morphology and findings in newborn infants. Z Geburtshilfe Perinatol 1987;191:814.

27. Williams LA, Evans SF, Newnham JP. Prospective cohort study of factors influencing the relative weigts of the plasenta and the newborn infant. BMJ 1997;314:1864-8.

28. Godfrey KM, Redman CW, Barker DJ, Osmond C. The effect of maternal anaemia and iron deficiency on the ratio of fetal weight to placental weight. Br J Obstet Gynaecol 1991;98:88691. 